\title{
Teses defendidas no Programa de Pós-Graduação Stricto Sensu em Educação da Universidade São Francisco no período de fevereiro a junho de 2017
}

LUVISON, Cidinéia da Costa. Narrar, dizer e vivenciar como apropriação e (re)significação de linguagens e conceitos matemáticos no $3^{\circ}$ ano do Ensino Fundamental. 2017. 227p. Tese (Doutorado em Educação). Programa de Pós-Graduação Stricto Sensu em Educação da Universidade São Francisco. Itatiba, SP, 2017. Orientadora: Profa. Dra. Luzia Batista de Oliveira Silva.

A presente pesquisa de doutorado, vinculada ao Projeto Observatório da Educação (Obeduc) e realizada de 2014 a 2016, buscou investigar - como as narrativas (orais e escritas), em ambientes de investigações matemáticas, com alunos do $3^{\circ}$ ano do Ensino Fundamental, podem potencializar a elaboração da linguagem e de conceitos matemáticosll. Teve como objetivos analisar: 1) a apropriação, pelos alunos, da linguagem e dos conceitos matemáticos na produção de diferentes registros e quando explorados durante a circulação de ideias em aulas de matemática; 2) os processos de mobilização do pensamento matemático escolar, em momentos de intervenção pedagógica e de socialização de ideias (comunicação matemática) e o modo como essa comunicação mobiliza o aluno a escrever e reescrever sobre suas hipóteses; 3 ) e a forma como essas narrativas impulsionam leitores e ouvintes a (re)significar e transformar seus próprios escritos, possibilitando que o letramento matemático ocorra. A produção dos dados foi realizada em uma escola pública municipal de Bragança Paulista-SP, em uma sala de aula do $3 .^{\circ}$ ano do Ensino Fundamental, em que a pesquisadora era professora. Utilizaram-se os dados registrados durante as tarefas propostas; a escrita de narrativas produzidas no diário de aprendizagem (Genimático) e no diário reflexivo da professora-pesquisadora; as videogravações; e fotografias. A pesquisa busca uma convergência de olhares entre Bakhtin, Paul Ricoeur, Vigotski e Walter Benjamin. A análise utilizouse dos episódios da sala de aula e das narrativas. Evidenciou-se a importância das narrativas (orais e escritas) no processo de apropriação da linguagem e da elaboração conceitual em matemática, viabilizado pela palavra, e sua ação no decorrer da escrita, da leitura e da comunicação de ideias, que mobilizam no aluno um ato responsivo, reflexivo conjunto e as práticas de letramento matemático. Em um ambiente de investigações em que as tarefas propostas possuem um caráter investigativo e problematizador, criam-se condições para que o aluno se sinta empoderado ao resolvê-las, num espaço-tempo planejado, dialógico, de pertença, de identidade e de experiências que podem ser renarradas e compartilhadas, pois formam-se e transformam-se a partir das múltiplas linguagens que circulam em sala de aula.

Palavras-chave: Letramento matemático; Obeduc; Narrativas; Apropriação da linguagem e elaboração conceitual; Ambientes de investigação matemática.

BOLOGNANI, Marjorie Samira Ferreira. Paisagens da formação de formadores: uma viagem pelas narrativas de gestoras pedagógicas. 2017. 212p. Tese (Doutorado em Educação). Programa de Pós-Graduação Stricto Sensu em Educação da Universidade São Francisco. Itatiba, SP, 2017. Orientadora: Profa. Dra. Adair Mendes Nacarato.

Esta pesquisa narrativa tem como foco a formação contínua de gestoras pedagógicas, da cidade de Jundiaí, interior de São Paulo. Foi realizada com quatro gestoras pedagógicas que atuam em escolas públicas da rede municipal: três coordenadoras pedagógicas e uma assistente de direção que desenvolve o trabalho pedagógico. Elas são denominadas, neste texto, de gestoras pedagógicas. A problematização, nascida a partir das questões deixadas pela pesquisa de mestrado, foi: "O que narram as gestoras pedagógicas que atuam na formação de professores, quando inseridas em um contexto de reflexão sobre as práticas escolares e problematização destas?". Teve-se como propósitos: tornar visíveis as trajetórias de vida das gestoras pedagógicas que atuam nos anos iniciais do Ensino Fundamental como estudantes, professoras e gestoras pedagógicas da rede municipal de Jundiaí; produzir sentidos para o modo como as gestoras pedagógicas se reconhecem profissionalmente, em um movimento entre a discussão coletiva e a compreensão individual, a partir das narrativas (orais e escritas) e da formação contínua em um grupo de discussão-reflexão; e identificar, nas narrativas, (re)significações da prática das gestoras pedagógicas, quando elas participam do grupo de discussão-reflexão. Os dados do estudo foram tratados narrativamente, e, para contar sua experiência, a pesquisadora usa a metáfora da viagem. Dialoga-se, 
nos referenciais teóricos e metodológicos, com autores que abordam narrativas da pedagogia, da literatura, da experiência e da (auto)formação, entre eles: Mikhail Bakhtin (1981, 2011); Walter Benjamin (1987a, 1987b); Antonio Bolívar, Jesús Domingo e Manuel Fernández (2001); D. Jean Clandinin e F. Michael Connelly (2011); Paulo Freire (1996, 2000); Marie-Christine Josso (2006, 2010a, 2010b, 2016); Sandra Jovchelovitch e Martin W. Bauer (2005); Wivian Weller (2006). Esta investigação também se baseia em estudiosos da Educação Matemática dos anos iniciais do Ensino Fundamental, como Adair Mendes Nacarato (1995, 2005, 2013, 2016). O material foi constituído de: Entrevistas Autobiográficas-Narrativas, transcrição dos encontros do grupo de discussão-reflexão, portfólio e notas de campo. O trabalho se enfoca, principalmente, no diálogo da pesquisadora com as gestoras pedagógicas, protagonistas da pesquisa. Essas conversas, teorias, metodologias e práticas e as narrativas de vida e de formação das participantes provocaram questões importantes para a discussão, a reflexão e a ação sobre um saber da experiência no município de Jundiaí. Além disso, refletiram sobre os saberes das práticas e os saberes teóricos, (re)significando a prática de gestão. As interpretações realizadas no estudo indicam que as gestoras têm o comprometimento com a formação docente na escola, o que se evidencia nos planejamentos e nas ações narradas e registradas. No entanto, as demandas externas, muitas vezes, comprometem o trabalho. Há, por conseguinte, a urgência de projetos de formação que atendam às reais necessidades das gestoras, preferencialmente de grupos de trabalho colaborativo, voltados para uma formação compartilhada. Os projetos de formação, por sua vez, precisam tomar as experiências das gestoras como foco para problematização e reflexão crítica.

Palavras-chave: Narrativas; Gestão pedagógica; Experiência; Matemática dos anos iniciais do Ensino Fundamental; Grupo de discussão-reflexão. 


\section{Dissertações defendidas no Programa de Pós-Graduação Stricto Sensu em Educação da Universidade São Francisco no período de fevereiro a junho de 2017}

BERBERT, Luzia de Almeida. Escola pública e família: uma abordagem baseada em documentos oficiais brasileiros. 2017. 62 p. Dissertação (Mestrado em Educação). Programa de Pós-Graduação Stricto Sensu em Educação da Universidade São Francisco. Itatiba, SP, 2017. Orientador: Prof. Dr. Nilo Agostini.

O presente trabalho analisa a função social da escola pública nos dias atuais e a relação da mesma com as famílias. Procurou-se, portanto, responder à seguinte questão norteadora: Escola e Família: é possível uma aproximação efetiva, levando em conta os contextos escolares nacionais, à luz da legislação vigente? Com o objetivo de identificar as dificuldades existentes na relação entre as instituições supracitadas e buscar possiblidades de efetivação da aproximação entre elas, bem como contribuir para que haja uma educação de qualidade, foram utilizados, como aporte teórico-metodológico, os estudos de Antunes (2013), Barbosa (2007), Dayrell (2007), Fini (2014), Freire (1996), Garcia (2008), Kaloustian (2011), Morin (2000), Oliveira (2014), Romanelli (2013) e alguns documentos oficiais brasileiros, como a Constituição Federal de 1988, o Estatuto da Criança e do Adolescente n ${ }^{\circ}$ 8069/1990 e a Lei de Diretrizes e Bases da Educação no 4024/1961. A partir da análise feita, é possível dizer que a família passou por muitas transformações ao longo dos anos e o fato de os pais, atualmente, precisarem se dedicar à vida profissional em período, muitas vezes, integral, têm pouco tempo para acompanhar e/ou nem acompanham o dia a dia dos filhos na escola. Isso pode ter resultados maléficos para a vida escolar de crianças, adolescentes e jovens. Podemos concluir que é possível efetivar a aproximação entre família e escola e desenvolver uma educação de qualidade, mas, para isso, é necessário o engajamento persistente das instituições em questão, da sociedade e do governo, garantindo políticas públicas que favoreçam tal aproximação.

Palavras - chave: família; escola pública; relacionamento; diálogo.

SILVA, Leonisia Bertolina da. O ensino de geometria nos anos iniciais do ensino fundamental: noções de espaço, ponto de referência e lateralidade. 2017. 120 p. Dissertação (Mestrado em Educação). Programa de PósGraduação Stricto Sensu em Educação da Universidade São Francisco. Itatiba, SP, 2017. Orientadora: Profa. Dra. Milena Moretto.

A presente pesquisa foi realizada no contexto do Projeto Observatório da Educação (OBEDUC/CAPES) e centra-se na parceria entre uma professora dos anos iniciais e a pesquisadora que desenvolveram uma sequência de atividades sobre geometria para um $1^{\circ}$ ano do Ensino Fundamental, em uma escola do município de Itatiba/SP, ao longo do $2^{\circ}$ semestre de 2015. Teve como objetivo geral compreender de que forma uma sequência de atividades planejadas pode contribuir no desenvolvimento da elaboração conceitual de crianças do $1^{\circ}$ ano do Ensino Fundamental no que se refere ao ensino da orientação espacial. Para tanto, tivemos como objetivos específicos: 1) buscar indícios dos modos que uma professora e uma pesquisadora, em parceria, possibilitaram o ensino da geometria espacial, a partir de uma sequência de atividades planejadas; e 2) analisar de que forma é possível os alunos produzirem conhecimentos geométricos, através da interação e do diálogo. Para fundamentar essa pesquisa, pautamo-nos na abordagem histórico-cultural. Utilizamos como procedimentos metodológicos para a produção de dados audiogravações e videogravações, diário de campo, os registros das crianças e narrativas de práticas produzidas pela professora regente. Os dados foram analisados a partir de três eixos temáticos: 1) uma discussão sobre o significado de ponto de referência; 2) o desenvolvimento das noções de lateralidade; e, 3) o uso de instrumentos mediadores para o desenvolvimento da aprendizagem. A análise mostrou-nos que a parceria entre a professora da turma e a pesquisadora, a dinâmica interativa ocorrida em sala de aula e o uso de instrumentos mediadores adequados no processo de ensino-aprendizagem possibilitaram aos alunos o desenvolvimento do pensamento geométrico, mais especificamente, das noções de espaço, ponto de referência e lateralidade.

Palavras-chave: Programa Observatório da Educação; Perspectiva Histórico-Cultural; Geometria Espacial; Ponto de referência; Lateralidade; Elaboração conceitual. 
PAIM, Marina Luz Rotava. Um olhar sensível para as narrativas e experiências de zeladores e serventes, os agentes de serviços gerais das escolas públicas em Chapecó-SC (1970 - 1980): potencialidades para a produção de conhecimento histórico. 2017. 164 p. Dissertação (Mestrado em Educação). Programa de PósGraduação Stricto Sensu em Educação da Universidade São Francisco. Itatiba, SP, 2017. Orientadora: Profa. Dra. Maria de Fátima Guimarães.

Nesta pesquisa, objetivamos olhar sensivelmente a modernização de Chapecó, no período de 1970 a 1980 , entretecendo as experiências e as memórias narradas por sujeitos escolares que viveram, nesse período, nessa cidade do oeste de Santa Catarina, como potencializadoras para a produção de conhecimento histórico. Justificamos este estudo por valorizarmos as narrativas dos serventes e zeladores, os agentes de serviços gerais, como sujeitos escolares que, muitas vezes, são esquecidos e silenciados no meio educacional. O critério de seleção desses sujeitos foi terem morado próximo ou nas escolas da rede pública estadual de Santa Catarina, da qual foram selecionadas duas escolas das existentes no período: Escola de Educação Básica Professora Zélia Scharf e Escola de Educação Básica Coronel Ernesto Bertaso. Ancoramo-nos, teórica e metodologicamente, na história cultural, com W. Benjamin, M. Bakhtin e E. P. Thompson e na história oral, com A. Portelli, E. Bosi e V. Alberti, ao trabalharmos com entrevistas semiestruturadas com esses sujeitos das duas escolas, e a leitura documental e as imagens monodológicas, conforme M. C. B. Galzerani, Benjamin e C. S. França. Esse aporte nos possibilitou olhar sensivelmente os rastros da modernização na cidade de Chapecó. Para tal, buscamos compreender e mobilizar a categoria conceitual um olhar sensível e quais são as potencialidades para pensar a estética da cidade e os sujeitos que a compõem, por meio das sensibilidades. Para problematizar a modernização de Chapecó, buscamos a contextualização histórico cultural de como ocorreu em Chapecó e no Brasil, a industrialização e urbanização das cidades, imbricadas nos novos projetos educacionais no período de 19701980, destacando as tensões e conflitos nas narrativas desses sujeitos escolares. Ressaltamos, ainda, a relevância social, científica e profissional da pesquisa por mobilizar diferentes olhares para o processo de modernização de Chapecó por meio de sujeitos esquecidos e silenciados do cotidiano escolar. Com olhar sensível, entretecemos, em uma leitura monodológica, as diferentes fontes pesquisadas entendendo-as como imagens dialéticas potencializadoras de conhecimento por meio da linguagem.

Palavras-chave: Narrativas; Experiências; Chapecó; Agentes de serviços gerais; Olhar sensível

SANTOS, Carla Cristiane Silva. O pensamento algébrico nos anos iniciais do ensino fundamental: a percepção de regularidade e o pensamento relacional. 2017. 182 p. Dissertação (Mestrado em Educação). Programa de Pós-Graduação Stricto Sensu em Educação da Universidade São Francisco. Itatiba, SP, 2017. Orientadora: Profa. Dra. Daniela Dias dos Anjos.

Esta pesquisa objetiva analisar como o trabalho com situações-problemas pode contribuir com o desenvolvimento do pensamento algébrico dos alunos dos anos iniciais do Ensino Fundamental. Parte-se de uma abordagem qualitativa, de natureza colaborativa, e da perspectiva histórico-cultural. Fez-se parceria com uma das professoras colaboradoras do Obeduc para aplicar duas sequências de tarefas para uma turma de $3^{\circ}$ ano do Ensino Fundamental de uma escola pública da rede municipal de Nazaré Paulista/SP. Realizou-se o trabalho no segundo semestre de 2015. A primeira sequência desenvolvida visava à percepção de regularidades em sequências matemáticas; a segunda centrou-se no trabalho com as noções de equivalência, feito com as Barras Cuisenaire e com a balança, para obter o pensamento relacional. Escolheu-se essas duas séries de atividades, pois elas são potencializadoras de generalizações matemáticas e, consequentemente, do pensamento algébrico, se propostas a partir de uma perspectiva investigativa e problematizadora. Visa-se responder à questão: "Quais indícios de pensamento algébrico podemos identificar nas estratégias de resolução de problemas, construídas por crianças de anos iniciais do Ensino Fundamental, a partir das percepções de regularidades em sequências e em relações de equivalência?". Para tanto, busca-se: identificar as ideias dos na resolução de problemas, considerando as regularidades em sequências; averiguar os indícios de pensamento algébrico manifestados pelos alunos; e analisar a interação em sala de aula e o papel da pesquisadora e da professora nesse processo. Os resultados indicam que as estratégias de resolução dos alunos podem ser tomadas como indícios de desenvolvimento do pensamento algébrico. Tais estratégias foram se transformando e avançando à medida que os estudantes investigavam a sequência de padrões matemáticos e exploravam as Barras Cuisenaire, em um 
ambiente problematizador. Além das tarefas em si, a socialização e a argumentação foram importantes para a constituição do pensamento algébrico, a partir de ideias implícitas e explícitas.

Palavras-Chave: Pensamento algébrico; Percepção de regularidade; Pensamento relacional; Álgebra nos anos iniciais; Padrões matemáticos.

BAPTISTA, Wesley. Patrimônio e educação das sensibilidades: por entre memórias e processos de significação do espaço urbano nas praças centrais da cidade de Bragança Paulista (2000-2015). 2017. $157 \mathrm{f}$. Dissertação (Mestrado em Educação). Programa de Pós-Graduação Stricto Sensu em Educação da Universidade São Francisco. Itatiba, SP, 2017. Orientadora: Profa. Dra. Maria de Fátima Guimarães.

Toda cidade pode ser estudada por suas características físicas e formais, mas, também, pelo processo de significação, ocupação e destinação do espaço, que não é neutro: é plural, polifônico e polissêmico. O traçado das ruas, a localização dos lugares de lazer, moradia e trabalho, bem como as edificações consideradas patrimônio cultural indicam que tal espaço acolhe a conformação de territórios e fronteiras em conexão com o fluxo de corpos e interesses distintos, atravessados por tensões, disputas e conflitos, matizados por símbolos, percepções e sensibilidades. Logo, o viver urbano propicia e mobiliza diferentes experiências que trazem indícios de uma educação das sensibilidades. Esta pesquisa focalizou as Praças José Bonifácio e Raul de Aguiar Leme, ambas ladeadas por edificações tombadas, situadas em Bragança Paulista. Teve por objetivos compreender experiências e sensibilidades urbanas plurais acerca dos jovens que transitaram por tais praças nos finais de semana, na relação com o patrimônio arquitetônico tombado; além disso, refletir sobre as percepções de patrimônio que se voltam para essas praças e para as edificações tombadas em seu entorno. Para tanto, com um enfoque de cunho qualitativo foi pesquisado: os processos de tombamento das edificações do período de 2000 a 2015, a legislação municipal, as fotografias, os periódicos e publicações de memorialistas locais, em franco diálogo com as algumas categorias conceituais que ampliaram e deram suporte à pesquisa, tais como, o conceito de experiência de W. Benjamin, as contribuições sobre patrimônio histórico-cultural do antropólogo J. R. Gonçalves, a categoria conceitual 'sensibilidades' de Pesavento, as contribuições sobre a história de Bragança Paulista e da colonização do presente pelo passado de Guimarães e o conceito estético e simbólico sobre o caminhar do arquiteto Francesco Careri e do filósofo Frederic Grós.

Palavras-chave: Educação das sensibilidades; Experiência; Patrimônio; Praça; Territorialidade.

HAYAKAWA, Thiago Alexandre. Faculdades Franciscanas: entrecruzando histórias e memórias do ensino superior na Região Bragantina (1970- 1980). 2017. 125 p. Dissertação (Mestrado em Educação). Programa de Pós-Graduação Stricto Sensu em Educação da Universidade São Francisco. Itatiba, SP, 2017. Orientadora: Profa. Dra. Maria de Fátima Guimarães.

Esta dissertação focaliza as Faculdades Franciscanas, as quais, então, compreendiam três campi distintos, localizados nas cidades de Bragança Paulista, Itatiba e São Paulo, inscrevendo-se no âmbito da história da educação superior no Brasil. O recorte temporal situa-se entre as décadas de 1970-80, levando-se em conta que em 1976 as faculdades e cursos superiores mantidos pelo Instituto de Ensino Superior da Região Bragantina passam para a administração da Casa de Nossa Senhora da Paz - Ação Social Franciscana, entidade coligada aos franciscanos da Província Franciscana da Imaculada Conceição do Brasil. E, em 1985, as Faculdades Franciscanas foram elevadas à condição de Universidade São Francisco. Os objetivos do trabalho foram: pesquisar a trajetória histórica das Faculdades Franciscanas, identificar a justificativa da Província Franciscana da Imaculada Conceição do Brasil para abrir uma nova frente de ação no ensino superior através das Faculdades Franciscanas e identificar a concepção de educação mobilizada nessa empreitada. No entrecruzamento das fontes documentais, observamos diferentes referências teóricas e uma práxis educacional que nos autorizaram a considerar que os franciscanos dialogavam com a teologia da libertação, o que confirmou a validade de nossos questionamentos iniciais. Nesta perspectiva, as contribuições teóricas de W. Benjamin, M. Bakhtin e E. P. Thompson foram fundamentais e possibilitam evidenciar as relações de poder que possivelmente matizaram tensões e disputas na trajetória das Faculdades Franciscanas.

Palavras-chave: Teologia da Libertação; História do Ensino Superior; Franciscanos na Educação; Faculdades Franciscanas. 